\title{
Three-Dimensional Electron Diffraction for Structural Analysis of Beam-Sensitive Metal-Organic Frameworks
}

\author{
Meng Ge, Xiaodong Zou and Zhehao Huang *(D) \\ Department of Materials and Environmental Chemistry, Stockholm University, 10691 Stockholm, Sweden; \\ meng.ge@mmk.su.se (M.G.); xzou@mmk.su.se (X.Z.) \\ * Correspondence: zhehao.huang@mmk.su.se
}

Citation: Ge, M.; Zou, X.; Huang, Z. Three-Dimensional Electron

Diffraction for Structural Analysis of Beam-Sensitive Metal-Organic Frameworks. Crystals 2021, 11, 263. https://doi.org/10.3390/ cryst11030263

Academic Editors: Anssi Peuronen and Thomas Roseveare

Received: 31 January 2021

Accepted: 2 March 2021

Published: 8 March 2021

Publisher's Note: MDPI stays neutral with regard to jurisdictional claims in published maps and institutional affiliations.

Copyright: (c) 2021 by the authors. Licensee MDPI, Basel, Switzerland. This article is an open access article distributed under the terms and conditions of the Creative Commons Attribution (CC BY) license (https:// creativecommons.org/licenses/by/ $4.0 /)$.

\begin{abstract}
Electrons interact strongly with matter, which makes it possible to obtain high-resolution electron diffraction data from nano- and submicron-sized crystals. Using electron beam as a radiation source in a transmission electron microscope (TEM), ab initio structure determination can be conducted from crystals that are 6-7 orders of magnitude smaller than using X-rays. The rapid development of three-dimensional electron diffraction (3DED) techniques has attracted increasing interests in the field of metal-organic frameworks (MOFs), where it is often difficult to obtain large and high-quality crystals for single-crystal X-ray diffraction. Nowadays, a 3DED dataset can be acquired in 15-250 s by applying continuous crystal rotation, and the required electron dose rate can be very low $\left(<0.1 \mathrm{e} \mathrm{s}^{-1} \AA^{-2}\right.$ ). In this review, we describe the evolution of 3DED data collection techniques and how the recent development of continuous rotation electron diffraction techniques improves data quality. We further describe the structure elucidation of MOFs using 3DED techniques, showing examples of using both low- and high-resolution 3DED data. With an improved data quality, 3DED can achieve a high accuracy, and reveal more structural details of MOFs. Because the physical and chemical properties of MOFs are closely associated with their crystal structures, we believe 3DED will only increase its importance in developing MOF materials.
\end{abstract}

Keywords: electron diffraction; electron crystallography; electron microscopy; metal-organic framework; crystal structure

\section{Introduction}

Metal-organic frameworks (MOFs) or porous coordination polymers (PCPs) are formed by coordination of metal ions or clusters with organic ligands. Due to their large surface areas, tunable pore structures, adjustable chemical functionality, and structural flexibility [1-6], MOFs have shown wide applications such as gas storage [7-10], separation [11-14], energy storage and conversion [15-20], drug delivery [21,22], sensing [23-26], catalysis [27-31], and bio-technological applications [32]. A deep understanding of their atomic structures is essential for utilizing their properties to develop new applications and design new MOFs. Various diffraction techniques have been applied for structure determination of MOF crystals, among which are single-crystal X-ray diffraction (SCXRD), powder X-ray diffraction (PXRD), and electron diffraction (ED).

SCXRD is currently the most common and mature technique for structure determination. A large variety of crystal structures of new materials has been solved using SCXRD [33]. However, structure determination by SCXRD requires large crystal sizes to be at least a few micrometers, and it is sometimes difficult to grow for MOF crystals. Many MOFs are synthesized as nano- or submicron-sized crystals, which are too small to be studied by SCXRD. In such cases, PXRD has been an alternative technique, by which data from millions of randomly oriented crystals are collected. However, the peak overlap of Bragg reflections in PXRD data leads to a major challenging for structure determination where extraction of the intensities of overlapped peaks is difficult. This drawback 
is more likely intensified for MOFs, which often have large unit cells or contain multiple crystalline phases.

Three-dimensional electron diffraction (3DED) techniques have been developed to overcome the size limitation imposed by SCXRD, which have been shown to be powerful for ab initio structure determination of nano- or submicron-sized crystals. Electrons interact much stronger with matter than X-rays do. By taking this advantage, therefore, ED data with a high signal-to-noise ratio can be obtained even for tiny crystals. During the past two decades, several research groups have independently developed different protocols of 3DED [34-44]. The principle of 3DED is to tilt the crystal around the goniometer axis in a TEM and record two-dimensional (2D) ED pattern at each tilt angle. Reconstructing the 2D ED patterns at different angles into a 3D reciprocal lattice allows for the determination of unit cell and space group. Further indexing the reflections and extracting their intensities provide the basis for determining the crystal structure by using e.g., direct methods, charge flipping, etc. Various studies have demonstrated that 3DED methods can effectively and accurately determine different kinds of structures of MOFs [45-47].

In this review, we describe the development of 3DED techniques, with a focus on recently developed continuous rotation data collection. Benefiting from the fast data collection, the continuous rotation methods exhibit significant advantages for structural analysis of MOFs, which are sensitive to radiation damage by electron beams. We explore the importance of minimizing radiation damage and improving data quality to achieve high accuracy and reliability of atomic structures obtained by 3DED. We choose several MOFs as examples to demonstrate the power of structure determination by 3DED, from low-resolution data $(\geq 1.3 \AA)$ to high-resolution data $(<1.3 \AA)$. Finally, we discuss the limitation and future perspectives of 3DED methods.

\section{Three-Dimensional Electron Diffraction (3DED) Methods}

Electron diffraction (ED) was first discovered in 1927 [48]. Structural analysis by ED has also a long history, with the first publication of structure determination by ED in 1937 [49]. Ab initio structure determination was conducted on different types of organic and inorganic crystals using ED patterns taken along different zone axes [50-54]. However, it is highly time-consuming to collect complete ED data and obtain integrated intensities based on zone axis patterns. It is also challenging to merge ED intensities from different zone axes to obtain 3D data. Furthermore, multiple scattering of electrons in the crystal results in dynamical effects, which are pronounced in zonal ED patterns.

Since the late $2000 \mathrm{~s}$, several groups have developed 3DED techniques to address the aforementioned drawbacks in using electron diffraction for structural analysis of nanoand submicron-sized crystals. Two groups led by Kolb and Hovmöller independently developed methods and software for 3DED data collection. The basic concept of 3DED is to rotate an arbitrarily oriented crystal by tilting a goniometer in a TEM and acquire a series of ED patterns at different goniometer tilt angles, so that 3D reciprocal space is sampled. Kolb et al. developed automated diffraction tomography (ADT) [34], which is performed in scanning transmission electron microscopy (STEM) mode. During the data collection of ADTs, the fine data sampling is achieved by combining goniometer tilt with electron beam precession using the beam tilt deflectors, which is also called precession electron diffraction tomography (PEDT) [35]. Hovmöller et al. developed rotation electron diffraction (RED) [36,37], which is performed in TEM mode using stepwise rotation. During the data collection of RED, the sampling is achieved by combining coarse goniometer tilt (e.g., $1.0-2.0^{\circ}$ /step) with fine beam tilt (e.g., $0.05-0.20^{\circ} /$ step) to cover the reciprocal space. Various software has been developed for processing 3DED data, and reconstruction and virtualization of reflections in $3 \mathrm{D}$ reciprocal space, i.e., RED data processing [37], ADT3D [55], PETS [56], and EDT-PROCESS [38]. From the reconstructed $3 \mathrm{D}$ reciprocal lattice, the unit cell parameters and space group can be determined, and the intensities can be integrated and extracted. The developments of 3DED have drastically 
simplified the data collection procedure, decreased the time needed for data collection, and reduced the effect of dynamical scattering.

Overcoming the size limitation of SCXRD, 3DED has been applied to study nanoand submicron-crystals of MOFs, whose structures are difficult or even impossible to be solved by SCXRD or PXRD [45-47]. However, due to the weak coordination interaction between inorganic metal ions and organic linkers, MOFs suffer more from electron beam damage than inorganic crystals, such as zeolites [57] and metal oxides [58]. This leads to crystal degradation during the 3DED data collection. As a result, data quality is limited, particularly in terms of data resolution, which needs to be higher enough to resolve individual atoms in MOF crystals for ab initio structure determination. While it is possible to obtain structural models from low resolution 3DED data, the data is not enough for structure refinement to validate the structural model. In such a case, other techniques, such as Rietveld refinement against PXRD, nuclear magnetic resonance (NMR) spectroscopy, etc. are often used as complementary methods to validate the structures obtained from 3DED data [59-62].

New 3DED protocols by applying continuous crystal rotation, denoted by different groups as continuous rotation electron diffraction (cRED) [43], Fast ADT [44], Fast-EDT [42], MicroED [41], and rotation electron diffraction [40], have been developed. As a result, these methods have greatly speeded up data collection, reduced beam damage, and improved data quality. In contrast to the stepwise 3DED techniques, 3DED data are recorded in a movie mode while the crystal is continuously rotated at a constant speed (Figure 1). Using this strategy, the total data collection time can be reduced to less than a few minutes, which drastically reduces the overall beam damage and prevents loss of crystallinity. Combining with a high-speed detector with fast readout time, the total electron dose applied on the crystal can be decreased, the missing data wedge in 3D reciprocal space can be minimized, and data quality can therefore be further improved. Because the recorded images represent integrated intensities over the desired exposure time for continuous rotation data, more accurate intensities can be obtained. In many cases, collecting the data at the cryogenic condition with a cooling holder can further mitigate the beam damage [63] and therefore improve data resolution. In practice, due to the sample drift caused by goniometer tilt, it is often difficult to keep the same crystal area selected for data acquisition using continuous rotation methods. To solve the problem, a crystal-tracking solution was developed by defocusing the diffraction patterns at regular intervals (e.g., after every 10 diffraction patterns), and the crystal can be re-centered either manually or automatically by software such as Instamatic $[43,64]$. For continuous rotation data, in addition to the software developed for processing stepwise 3DED data [65,66], software developed for X-ray crystallography, such as XDS [67], DIALS [68], and MOSFLM [69] can be adapted for data reduction and intensity extraction. Using kinematical approximation, ab initio structure solution can be performed in a similar manner as for SCXRD by applying direct methods, charge flipping, etc., with software such as SHELX [70,71], SIR [72], and JANA [73]. Notably, during data processing, wavelength and atomic scattering factors for electrons should be used instead of those for X-rays. Electron beam damage could be further reduced using serial electron diffraction (SerialED), where one single ED pattern is obtained per crystal with a throughput of thousands of ED patterns per hour [43]. Recent publications show that SerialED could enhance the resolution and signal-to-noise ratio of the data [74,75]. However, unit cell parameters are required for processing and indexing of SerialED data, which is an obstacle for the study of new materials, e.g., new MOFs. On the other hand, the development of serial rotation electron diffraction (SerialRED) allows automated cRED data acquisition, with a throughput of hundreds of crystals per hour [76]. An automated data processing pipeline was developed to process the SerialRED data, group and identify various phases in the sample by hierarchical cluster analysis based on the matching of unit cells and diffraction intensities [76]. With such advantages of the latest developments on 3DED methods, the number of MOF structures determined by 3DED keeps increasing. 
(a)

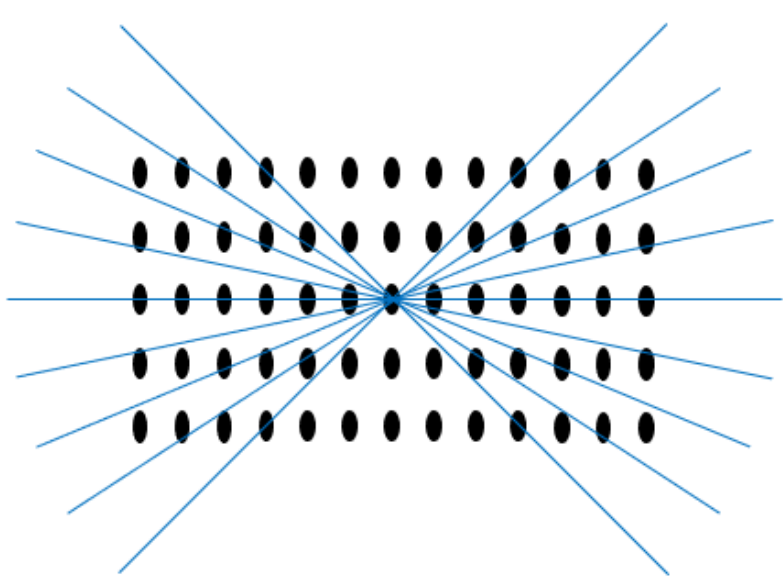

(b)

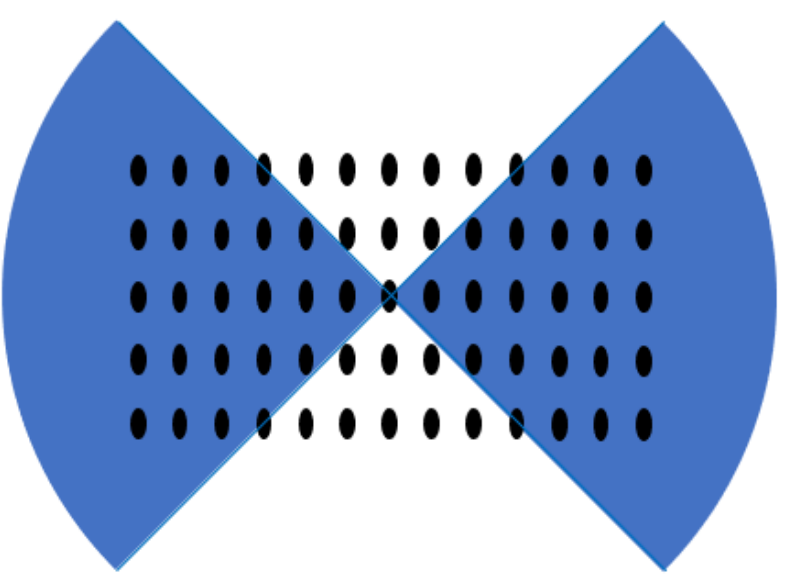

Figure 1. Illustration of (a) stepwise and (b) continuous rotation methods for three-dimensional electron diffraction (3DED) data collection. For stepwise rotation in (a), the crystal can be centered at each step. Fine steps are required in order to sample the reciprocal lattice and accurately estimate the intensities. For continuous rotation in (b), integrated intensities are obtained which are more accurate than stepwise rotation. Continuous rotation prefers detectors with a short readout time to avoid missing data during the detector readout.

\section{Applications of 3DED on MOFs}

As 3DED provides advantages on structural analysis of nano- and submicron-sized crystals, a growing number of MOFs whose structures cannot be studied by SCXRD have been determined by 3DED (Table 1). In this section, we present various examples of structure determination of MOFs using both low resolution $(\geq 1.3 \AA)$ and high-resolution $(<1.3 \AA)$ 3DED data. We first describe early applications with generally low data resolutions, followed by applications using high-resolution data obtained with improved 3DED techniques. We explore the importance of improving data resolution to reveal more structural details and achieve high accuracy and reliability of structural models.

Table 1. List of selected metal-organic framework (MOF) structures determined using 3DED.

\begin{tabular}{|c|c|c|c|c|}
\hline MOF Name & 3DED Protocol & Resolution (Å) & $\begin{array}{c}\text { Year of } \\
\text { Publication }\end{array}$ & Reference \\
\hline \multicolumn{5}{|c|}{ Low Resolution $(\geq 1.3 \AA)$} \\
\hline MFU-41 & ADT & 1.3 & 2011 & [59] \\
\hline SUMOF-7III(La) & RED & 3.57 & 2015 & [60] \\
\hline MIL-103 & RED & 1.82 & 2015 & {$[60]$} \\
\hline PCN-128W & RED & 1.4 & 2015 & [61] \\
\hline PCN-333(Al) & RED & 5.0 & 2015 & {$[62]$} \\
\hline $\mathrm{COK}-47_{\mathrm{L}}$ & cRED & 1.35 & 2019 & [77] \\
\hline BUT-33 & cRED & 1.5 & 2020 & [78] \\
\hline $\mathrm{Cu}_{3} \mathrm{HHTT}_{2}$ & cRED & 1.5 & 2020 & [79] \\
\hline \multicolumn{5}{|c|}{ High Resolution $(<1.3 \AA$ ) } \\
\hline CAU-7 & ADT & 1.15 & 2012 & [80] \\
\hline SUMOF-7I(La) & RED & 1.05 & 2015 & [60] \\
\hline SUMOF-7II(La) & RED & 1.23 & 2015 & {$[60]$} \\
\hline Bismuth subgallate & cRED & 0.7 & 2017 & [81] \\
\hline ICR-2 & EDT & 1.0 & 2018 & [82] \\
\hline sc-CCMOF-1 & EDT & 1.0 & 2018 & [83] \\
\hline Zr-CAU-30 & ADT & 1.0 & 2018 & [84] \\
\hline PCN-415 & cRED & 0.75 & 2018 & [85] \\
\hline PCN-416 & cRED & 1.05 & 2018 & [85] \\
\hline
\end{tabular}


Table 1. Cont.

\begin{tabular}{ccccc}
\hline MOF Name & 3DED Protocol & Resolution (Å) & $\begin{array}{c}\text { Year of } \\
\text { Publication }\end{array}$ & Reference \\
\hline Co-CAU-36 & cRED & 0.83 & 2018 & {$[86]$} \\
CAU-23 & cRED & 1.13 & 2019 & {$[87]$} \\
CAU-26 & ADT & 1.3 & 2019 & {$[88]$} \\
CAU-27-BDC & ADT & 1.0 & 2019 & {$[88]$} \\
SU-100 & cRED & 1.0 & 2020 & {$[89]$} \\
SU-100-HT & cRED & 0.8 & 2020 & {$[89]$} \\
Ga(OH)(1,4-ndc) & cRED & 0.8 & 2020 & {$[90]$} \\
cc $_{2}(1,4-N D C)_{3}$ & cRED & 0.8 & 2020 & {$[91]$} \\
Zn-MOF-888 & cRED & 1.1 & 2020 & {$[92]$} \\
CTH-11 & cRED & 1.1 & 2020 & {$[92]$} \\
CAU-45 & cRED & 0.8 & 2020 & {$[93]$} \\
PCN-226 & cRED & 1.15 & 2020 & {$[94]$} \\
ZIF-CO $3-1$ & cRED & 1.0 & 2020 & {$[95,96]$} \\
SU-101 & cRED & 0.8 & 2020 & {$[97]$} \\
ZIF-8 & MicroED & 0.87 & 2020 & {$[98]$} \\
\hline
\end{tabular}

\subsection{Structural Elucidation Using Low-Resolution 3DED Data}

The resolution of 3DED data from a MOF crystal is affected by many factors, for example, the crystallinity of the MOF, the stability of the MOF in vacuum and under the electron beam. Data resolution can be improved by reducing the total electron dose used for 3DED data collection. Stepwise 3DED data collection by ADT and RED, which were first developed, often requires higher electron doses and much longer data collection time compared to continuous rotation 3DED. Therefore, early examples of structure determination of MOFs using stepwise rotation for 3DED data collection, often have poor data resolution (>1.3 $)$. In such cases, direct phasing of 3DED data and subsequent least-squares structure refinement were almost impossible. However, the unit cell and space group determined by 3DED can be used for structure solution by real space approaches such as simulate annealing and model building. The resulting structural models need to be further verified and refined using complementary techniques such as PXRD and NMR.

For example, the structures of a series of isoreticular lanthanide-based MOFs were determined using RED data [60]. Built from lanthanide chains and tritopic linkers, the SUMOF-7I to -7IV have expanding pore diameters from 8.4 to $23.9 \AA$ A. (Figure 2). It was unsuccessful in producing sufficiently large crystals of SUMOF-7II, III, and IV for SCXRD. Instead, RED was employed for the structure determination of the SUMOF-7s. The resolution of RED data decreased with the increasing size of the linkers, from $1.05 \AA$ for SUMOF-7I(La), $1.23 \AA$ for SUMOF-7II(La), to $3.57 \AA$ for SUMOF-7III(La). As the resolution of the RED data was too low to ab initio determine the structure of SUMOF-7III(La), a structural model was built based on the obtained unit cell by using reticular chemistry. The structural models were further refined against the high-quality PXRD data by Rietveld refinement. SUMOF-7I, 7II, and -7III exhibit permanent porosity and high thermal and chemical stability.

RED was applied to obtain the key structural information of PCN-333(Al). It reveals that the crystal system is cubic with a large $a$ parameter $(\approx 127 \AA)$. The space group was determined to be $F d-3 m$ by combining RED and HRTEM [62]. With this important information, PCN-333(Al) was determined by model building and refined against PXRD data despite the limited data resolution (5 $)$ ). The structural analysis revealed that the PCN-333(Al) MOF contains ultra-large mesoporous cages which could encapsulate enzymes. In another example for the structure determination of PCN-128W, the unit cell parameters and space group were successfully determined from RED data with a resolution of $1.4 \AA$. An initial structural model was obtained by direct methods. However, the resolution was insufficient for structure refinement. The structure of PCN-128W was subsequently refined against synchrotron PXRD data using the Rietveld method. It reveals that the crystal structure of 
PCN-128W consists of $\mathrm{Zr}_{6}$ clusters linked by rectangular $4^{\prime}, 4^{\prime \prime \prime}, 4^{\prime \prime \prime \prime}, 4^{\prime \prime \prime \prime \prime \prime \prime \prime}$-(ethene-1,1,2,2tetrayl)tetrakis-(([1,1'-biphenyl]-4-carboxylic acid)) $\left(\mathrm{H}_{4} \mathrm{ETTC}\right)$ planar ligands and exhibits an interesting piezofluorochromic behavior [61].

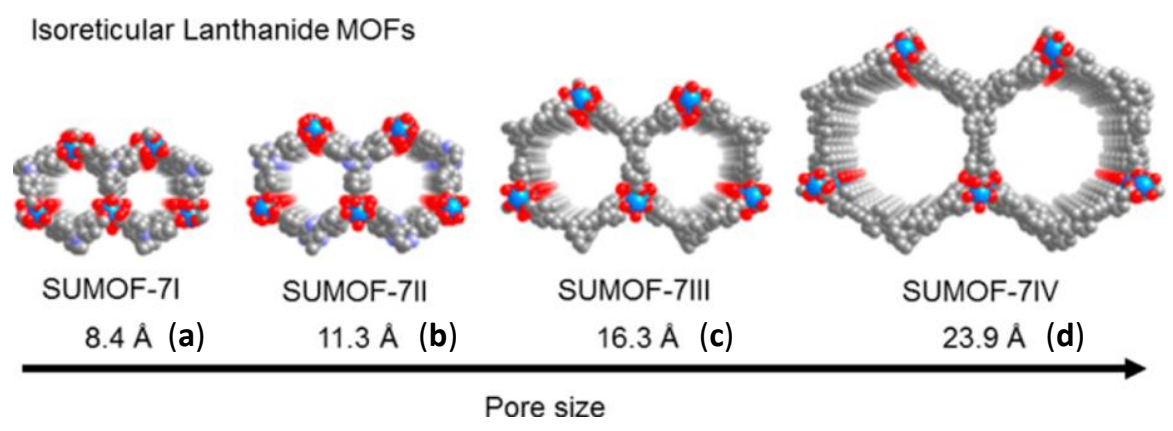

Figure 2. Crystal structures of SUMOF-7I (a), SUMOF-7II (b), SUMOF-7III (c), and SUMOF-7IV (d). The diameters of the corresponding pore apertures are 8.4,11.3, 16.3, and $23.9 \AA$, respectively (taking into account the van der Waals radii of the atoms) [60]. Reproduced from ref. [60] with permission from the American Chemical Society, copyright 2015.

\subsection{Structural Elucidation Using High-Resolution 3DED Data}

With the development of continuous rotation methods, ultrafast 3DED data collection can be achieved using a high rotation speed $(>0.4 \% \mathrm{~s})$, and a complete dataset can be obtained in $15-250 \mathrm{~s}$. A low electron dose rate $\left(<0.1 \mathrm{e} \AA^{-2} \mathrm{~s}^{-1}\right)$ can be applied to reduce electron beam damage. These advances have significantly improved the 3DED data quality. For most MOFs, it is possible to collect high resolution 3DED data $(0.7-1.1 \AA$, Table 1$)$. With a resolution better than $1.3 \AA$, the structures of MOFs can be solved ab initio from the 3DED data by direct phasing methods such as direct methods and charge flipping. More importantly the structural model can be refined against 3DED intensities. In addition, with improved data quality, more structural details can be revealed, which provides fundamental knowledge regarding the physical and chemical properties of MOFs. For example, cRED was used to determine the structure of CAU-23 (Figure 3), which crystallized as nano-sized particles of $\sim 200 \mathrm{~nm}$. Low dose illumination and fast data acquisition were applied to collect cRED data. The cRED data has a resolution of $1.13 \AA$, which is high enough for $\mathrm{ab}$ initio structure determination. The structure was therefore solved and refined from the cRED data, and all framework atoms were located with high precision and agreement values [87]. The framework structure of CAU-23 is chiral with a non-centrosymmetric space group. Four consecutive trans and cis corner-sharing $\mathrm{AlO}_{6}$ polyhedra formed the rod-shaped inorganic building unit. CAU-23 has a high-water sorption capacity, which makes it as an ideal material for ultra-low temperature adsorption driven chillers.

The structures of two isoreticular MOFs named PCN-415 and PCN-416 were successfully determined from cRED data at 0.75 and $1.05 \AA$ resolution, respectively (Figure 4) [85]. PCN-415 was synthesized by linking the $\left[\mathrm{Ti}_{8} \mathrm{Zr}_{2} \mathrm{O}_{12}(\mathrm{MeCOO})_{16}\right]$ clusters and 1,4-benzenedicarboxylate (BDC) linkers. Extension of BDC into 2,6-naphthalenedicarboxylate (NDC) gives rise to an isoreticular MOF, PCN-416. Due to the small crystal sizes of PCN-415 and PCN-416, cRED was applied to both solve and refine the structures. In addition, the structural models were compared with those refined against PXRD. The atomic positions refined by cRED and PXRD are very similar and differ on average by $0.032 \AA$ for $\mathrm{Zr}$ and Ti atoms and by $0.071 \AA$ for $\mathrm{O}$ and $\mathrm{C}$ atoms. The small deviation demonstrates high accuracy and reliability of the 3DED method. Importantly, the high-resolution data enables precise locations of $\mathrm{Ti}$ and $\mathrm{Zr}$ in the mixed metal cluster, which is crucial for understanding the photoactivity of PCN-145 and PCN-416 and their utilization as photocatalysts for hydrogen generation. 
(a)

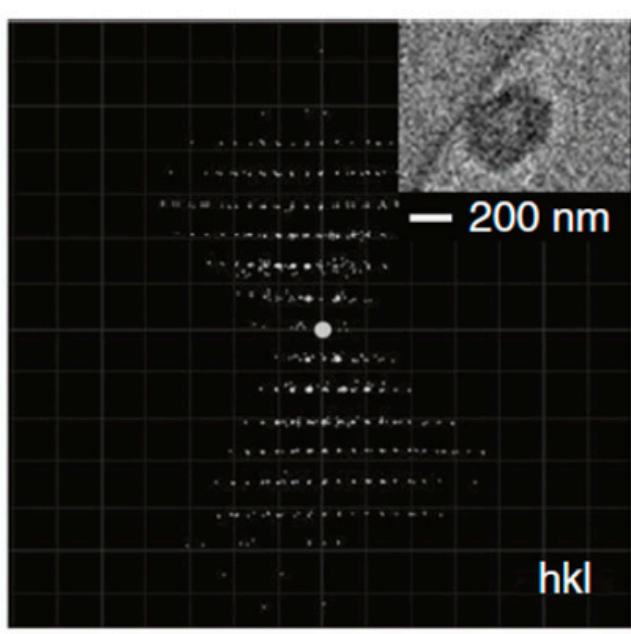

(b)

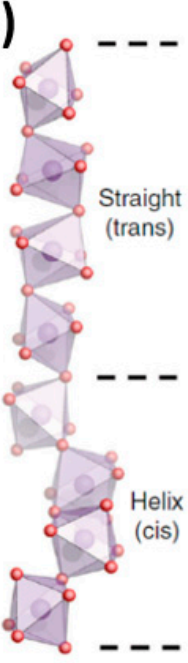

(c)

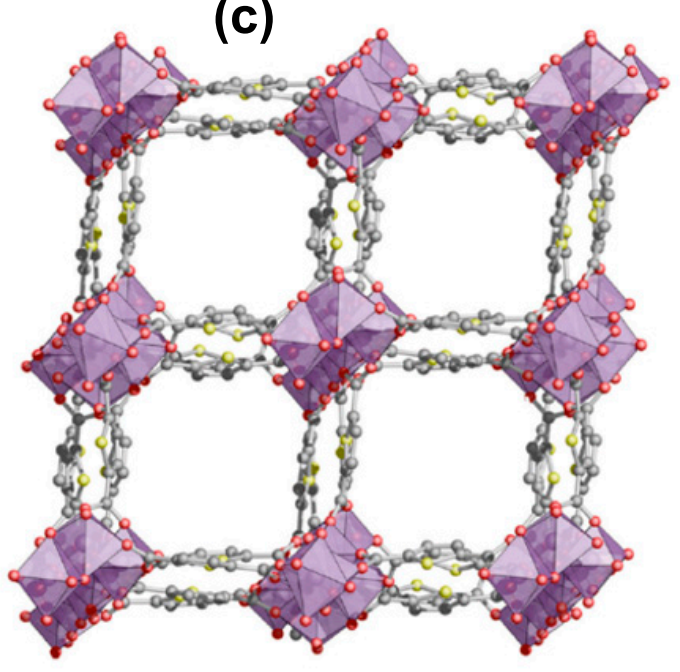

Figure 3. (a) Reconstructed 3D reciprocal lattice from cRED data of a nano-sized single-crystal (inset) of CAU-23. (b) The repetition of cis and trans corner-sharing $\mathrm{AlO}_{6}$ polyhedra forming the inorganic building unit of CAU-23. (c) The 3D structure of CAU-23 projected along [010]; water molecules are omitted for clarity [87]. Reproduced from ref. [87] with permission from the Springer Nature, copyright 2019.

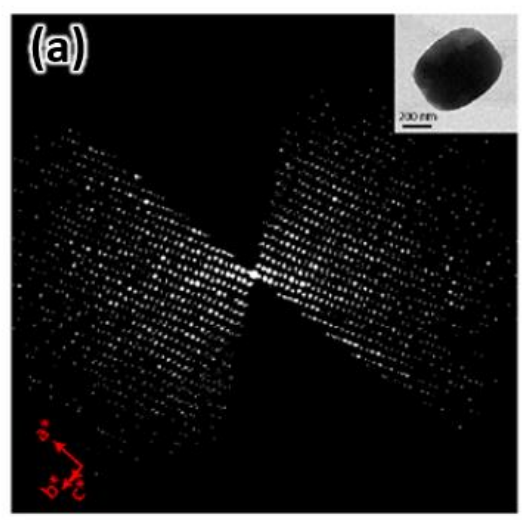

(c)

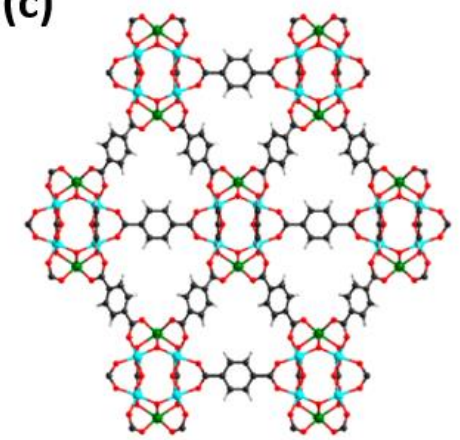

$\mathrm{PCN}-415$
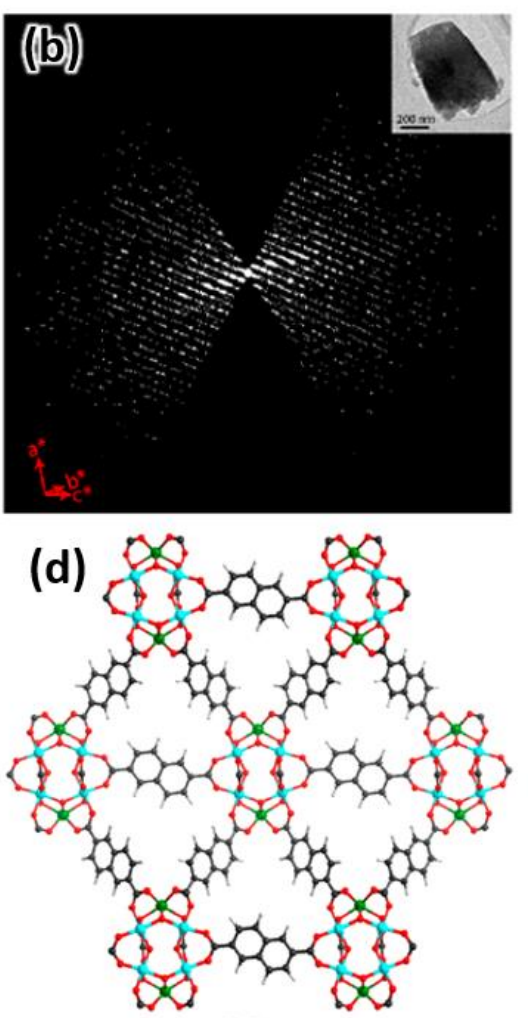

$\mathrm{PCN}-416$

Figure 4. Reconstructed 3D reciprocal lattice of (a) PCN-415 and (b) PCN-416 from cRED data. Insets are the crystals from which the RED data were collected. (c) and (d) Structure of PCN-415 and PCN-416 built from $\left[\mathrm{Ti}_{8} \mathrm{Zr}_{2} \mathrm{O}_{12}(\mathrm{RCOO})_{16}\right.$ ] clusters and different carboxylate linkers [85]. Reproduced from ref. [85] with permission from the American Chemical Society, copyright 2018.

CAU-45 is an example of a mesoporous MOF solved by direct phasing of cRED data [93]. Its structure could be solved from a cRED dataset collected in less than $1.5 \mathrm{~min}$. The data resolution was better than $0.8 \AA$. Multiple cRED datasets were merged to increase 
the data completeness. The structure was refined using the high-quality cRED data. In addition to the framework structure, the hydrogen bond network and disorders of the amide groups could be identified from the refinement against the cRED data. CAU45 exhibits a honeycomb structure of stacked layers which comprise both hexa- and dodecanucelar zirconium clusters (Figure 5).

With the improvement of 3DED data quality, it is possible to locate guest species in the pores of MOFs. Using cRED data collected at low sample temperature (96 K), the structure of a novel porous cobalt MOF, Co-CAU-36, was determined (Figure 6) [86]. Co-CAU-36 was synthesized using $\mathrm{Co}(\mathrm{II})$ as the metal ion and tetracarboxyporphyrin $\left(\mathrm{H}_{6} \mathrm{TCPP}\right)$ as the linker in a solvent mixture containing 1,4-diazabicyclo[2.2.2] octane (DABCO), $\mathrm{HCl}$, and water. Eight high resolution cRED datasets $(0.83-1.00 \AA)$ were obtained from different crystals. Accurate structural models were determined from each of the eight datasets. Notably, not only the framework atoms but also solvent DABCO and $\mathrm{H}_{2} \mathrm{O}$ molecules in the pores could be located after analyzing the difference Fourier maps. Furthermore, hydrogen bonds were observed between the DABCO and the framework, as well as between the water molecules, which are crucial to stabilize the solvent molecules.

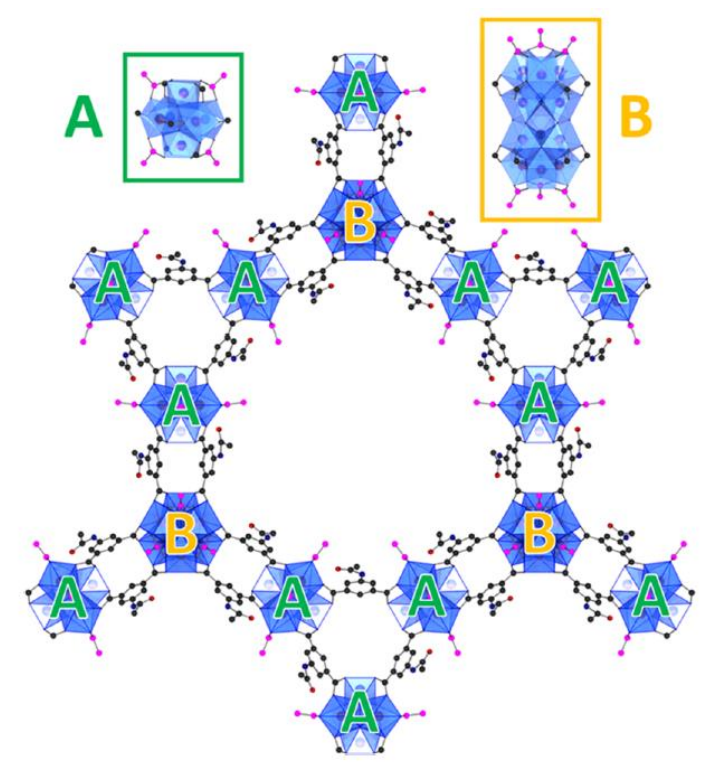

Figure 5. Inorganic building units (IBUs) of CAU-45 and interconnection to a layered motive via 5-acetamidoisophthalate ions. (A) Hexanuclear clusters. (B) Dodecanuclear clusters. Zirconium-oxygen clusters: blue; linker carbon: black; acetate carbon: pink; oxygen: red; nitrogen: dark blue; hydrogen: not displayed [93]. Reproduced from ref. [93] with permission from the American Chemical Society, copyright 2020.

A zeolitic imidazolate framework $\mathrm{ZIF}-\mathrm{CO}_{3}-1$ was another example whose structure was ab initio determined using high-resolution cRED data (1.0 $⿱$ ) [96]. ZIF- $\mathrm{CO}_{3}-1$ was built by linking $\mathrm{Zn}(\mathrm{II})$ cations with 2-methylimidazolate $\left(\mathrm{mIM}^{-}\right)$and carbonate $\left(\mathrm{CO}_{3}{ }^{2-}\right)$ ions. To assess the accuracy of structure determination by 3DED, the final structural model of ZIF- $\mathrm{CO}_{3}-1$ refined against $\mathrm{CRED}$ data was compared to that refined against SCXRD data (Figure 7) $[95,99]$. Although the $R_{1}$ value of cRED data $(0.227)$ is higher than that of SCXRD data (0.049), the two structural models are very similar, with an average deviation of $0.06(1)$ $\AA$ for the heavy $\mathrm{Zn}$ atom and 0.07(3) $\AA$ for light atoms including N, C, and O (Figure 7). The average deviation for the bond lengths and angles are $0.04(3) \AA$ and $4(3)^{\circ}$, respectively. The small deviation suggests that the structural models obtained by using high quality $3 \mathrm{DED}$ data are as accurate and reliable as those obtained by SCXRD. The high $R_{1}$-values, therefore, are mainly caused by dynamical effects, because the 3DED intensities are treated as kinematical intensities in structure refinement using X-ray crystallography software, such as SHELX and JANA. 

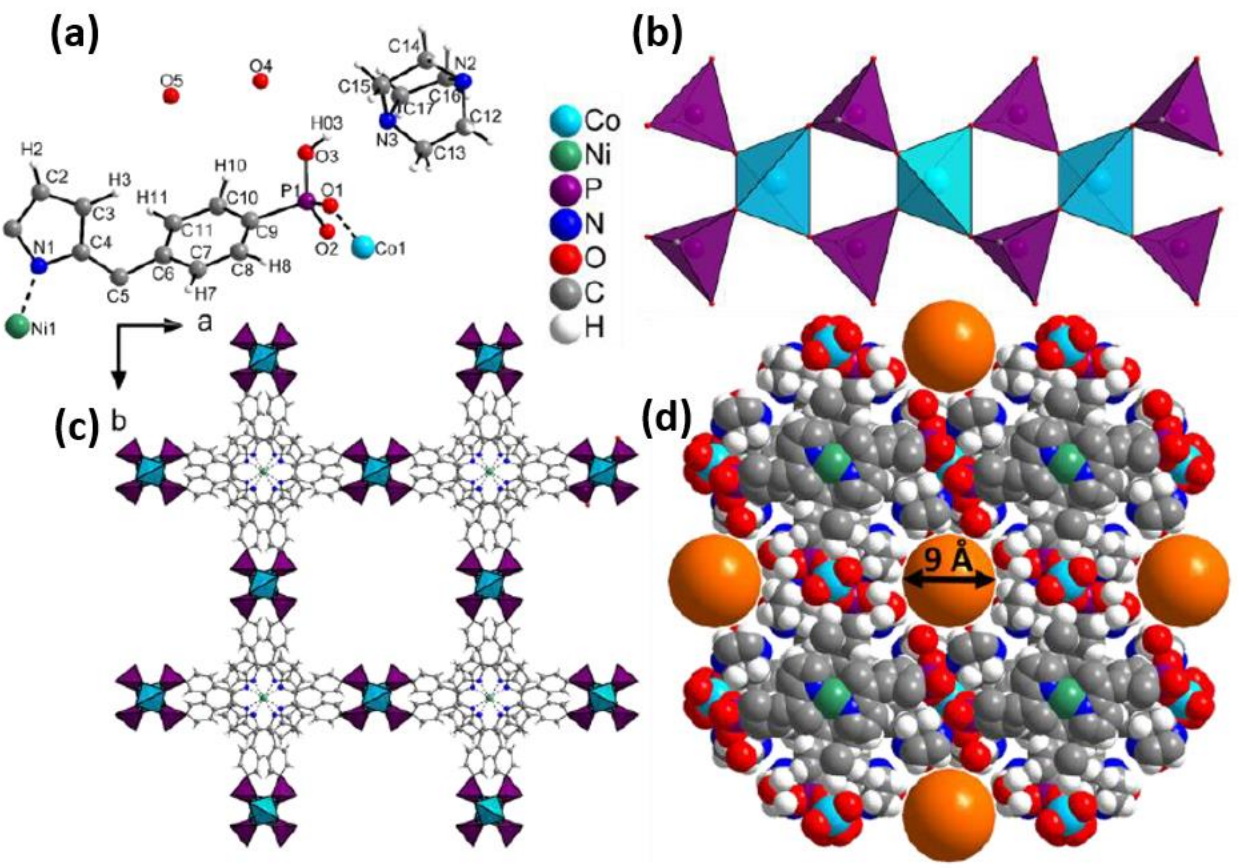

Figure 6. Structure of Co-CAU-36. (a) The details of the structure showing possible $\mathrm{H}$ bonds between the DABCO molecule and the phosphonate group on the porphyrin. (b) The $1 \mathrm{D} \mathrm{CoO}-\mathrm{PO}_{4}$ tetrahedral chain along the c-axis. (c) The structure of Co-CAU-36 viewed along the c-axis. (d) The ball filling model of the structure with the guest molecules shows the pore diameter of $9 \AA$. Reproduced from ref. [86] with permission from the John Wiley \& Sons, Inc., copyright 2018.

a

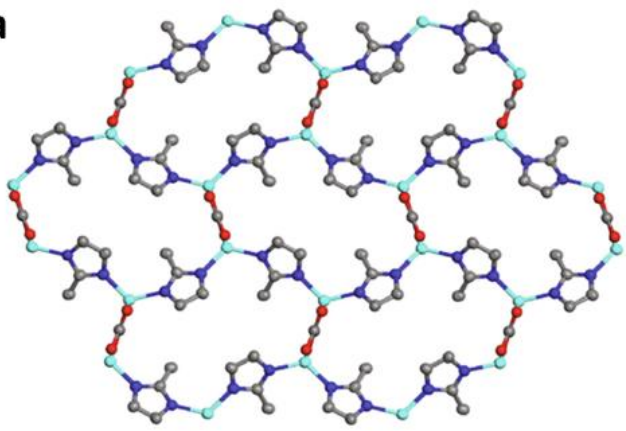

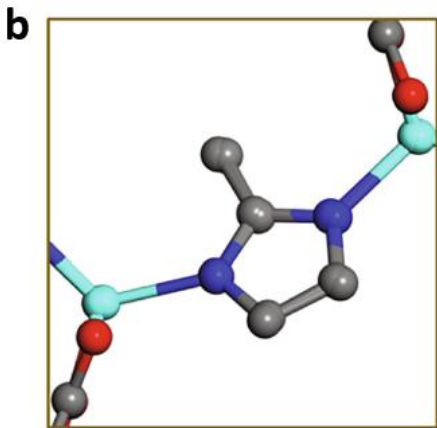

Figure 7. Comparison between the structural model of BSA@ZIF-C refined from cRED data and that of ZIF-CO3-1 from SCXRD data [95]. (a) The structures are stacked together, viewed along the c-axis. (b) An enlarged figure shows the connection of a mIM linker to $\mathrm{Zn}$ (II) cations, illustrating the accuracy of the model obtained from the cRED data. Blue spheres: N; red spheres: O; gray spheres: C; cyan spheres: $\mathrm{Zn}$ atoms. Reproduced from ref. [95] with permission from the Royal Society of Chemistry, copyright 2021.

\section{Summary and Outlook}

In this review, we describe the development of using 3D electron diffraction for structure determination and the recent advances of 3DED techniques from stepwise rotation to continuous rotation. The continuous rotation methods provide cutting edges to minimize beam damage and improve data quality. We describe the structure determination of MOFs by using low resolution $(\geq 1.3 \AA)$ and high resolution $(<1.3 \AA)$ 3DED data. For low-resolution data, key structural information such as unit cell parameters and space groups can be determined from 3DED data. Further structure determination requires a combination with other characterization techniques. For high-resolution data, structure determination using 3DED can be as accurate as SCXRD does. With the improvement 
of data quality, detailed structural information such as the location of guest molecules, hydrogen-bonding networks can also be obtained.

Despite the achievements of 3DED methods, more efforts are needed to further develop 3DED techniques and explore their applications in MOF materials. As hardware, especially detectors, are crucial for obtaining high quality data, faster and more sensitive detectors are needed to further improve data resolution. Overcoming dynamical effects caused by multiple scattering is another challenge, which hinders discovering more structural details of MOFs. The loss of crystallinity caused by vacuum can be prevented by applying cryo-EM techniques. However, cryo-EM techniques are mostly based on aqueous solutions. As most MOFs crystallize in organic solvents and could be unstable in aqueous solutions, further development of organic solvent based cryo-EM techniques is desired to prevent damage of MOFs in vacuum.

With the fast development of 3DED techniques, we believe 3DED will become a widespread technique to provide accurate and reliable structural models for MOFs. Predictably, by taking the advantages of 3DED for structural analysis, it will certainly accelerate research in the field of MOFs.

Author Contributions: Z.H. conceived the idea. M.G. and X.Z. prepared an initial draft of the manuscript. All authors have participated in the writing of the final manuscript, and agreed to the published version of the manuscript.

Funding: This work was funded by the Swedish Research Council (VR, 2016-04625, Z.H. and 201704321, X.Z.) and the Swedish Research Council Formas (2020-00831, Z.H.).

Conflicts of Interest: There is no conflict to declare.

\section{References}

1. Yaghi, O.M.; Li, G.; Li, H. Selective binding and removal of guests in a microporous metal-organic framework. Nature 1995, 378, 703-706. [CrossRef]

2. Kitagawa, S.; Kitaura, R.; Noro, S. Functional porous coordination polymers. Angew. Chem. Int. Ed. 2004, 43, $2334-2375$. [CrossRef] [PubMed]

3. Eddaoudi, M.; Kim, J.; Rosi, N.; Vodak, D.; Wachter, J.; O'Keeffe, M.; Yaghi, O.M. Systematic design of pore size and functionality in isoreticular MOFs and their application in methane storage. Science 2002, 295, 469-472. [CrossRef] [PubMed]

4. Schneemann, A.; Bon, V.; Schwedler, I.; Senkovska, I.; Kaskel, S.; Fischer, R.A. Flexible metal-organic frameworks. Chem. Soc. Rev. 2014, 43, 6062-6096. [CrossRef]

5. Lo, S.-H.; Feng, L.; Tan, K.; Huang, Z.; Yuan, S.; Wang, K.-Y.; Li, B.-H.; Liu, W.-L.; Day, G.S.; Tao, S.; et al. Rapid desolvationtriggered domino lattice rearrangement in a metal-organic framework. Nat. Chem. 2020, 12, 90-97. [CrossRef] [PubMed]

6. Yuan, S.; Huang, L.; Huang, Z.; Sun, D.; Qin, J.-S.; Feng, L.; Li, J.; Zou, X.; Cagin, T.; Zhou, H.-C. Continuous variation of lattice dimensions and pore sizes in metal-organic frameworks. J. Am. Chem. Soc. 2020, 142, 4732-4738. [CrossRef] [PubMed]

7. Li, H.; Eddaoudi, M.; Groy, T.L.; Yaghi, O.M. Establishing microporosity in open metal- organic frameworks: Gas sorption isotherms for $\mathrm{Zn}$ (BDC)(BDC = 1, 4-benzenedicarboxylate). J. Am. Chem. Soc. 1998, 120, 8571-8572. [CrossRef]

8. Li, Q.; Zhang, W.; Miljanić, O.Š.; Sue, C.-H.; Zhao, Y.-L.; Liu, L.; Knobler, C.B.; Stoddart, J.F.; Yaghi, O.M. Docking in metal-organic frameworks. Science 2009, 325, 855-859. [CrossRef]

9. Trickett, C.A.; Helal, A.; Al-Maythalony, B.A.; Yamani, Z.H.; Cordova, K.E.; Yaghi, O.M. The chemistry of metal-organic frameworks for $\mathrm{CO}_{2}$ capture, regeneration and conversion. Nat. Rev. Mater. 2017, 2, 1-16. [CrossRef]

10. Chen, Z.; Li, P.; Zhang, X.; Li, P.; Wasson, M.C.; Islamoglu, T.; Stoddart, J.F.; Farha, O.K. Reticular access to highly porous acs-MOFs with rigid trigonal prismatic linkers for water sorption. J. Am. Chem. Soc. 2019, 141, 2900-2905. [CrossRef] [PubMed]

11. Li, J.-R.; Sculley, J.; Zhou, H.-C. Metal-organic frameworks for separations. Chem. Rev. 2012, 112, 869-932. [CrossRef]

12. Duan, J.; Jin, W.; Kitagawa, S. Water-resistant porous coordination polymers for gas separation. Coord. Chem. Rev. 2017, 332, 48-74. [CrossRef]

13. Bobbitt, N.S.; Mendonca, M.L.; Howarth, A.J.; Islamoglu, T.; Hupp, J.T.; Farha, O.K.; Snurr, Q. Metal-organic frameworks for the removal of toxic industrial chemicals and chemical warfare agents. Chem. Soc. Rev. 2017, 46, 3357-3385. [CrossRef] [PubMed]

14. Lin, R.-B.; Xiang, S.; Xing, H.; Zhou, W.; Chen, B. Exploration of porous metal-organic frameworks for gas separation and purification. Coord. Chem. Rev. 2019, 378, 87-103. [CrossRef]

15. Zhang, T.; Lin, W. Metal-organic frameworks for artificial photosynthesis and photocatalysis. Chem. Soc. Rev. 2014, 43, 5982-5993. [CrossRef] [PubMed]

16. Sheberla, D.; Bachman, J.C.; Elias, J.S.; Sun, C.-J.; Shao-Horn, Y.; Dincă, M. Conductive MOF electrodes for stable supercapacitors with high areal capacitance. Nat. Mater. 2017, 16, 220-224. [CrossRef] 
17. Feng, D.; Lei, T.; Lukatskaya, M.R.; Park, J.; Huang, Z.; Lee, M.; Shaw, L.; Chen, S.; Yakovenko, A.A.; Kulkarni, A.; et al. Robust and conductive two-dimensional metal- organic frameworks with exceptionally high volumetric and areal capacitance. Nat. Energy 2018, 3, 30-36. [CrossRef]

18. Park, J.; Lee, M.; Feng, D.; Huang, Z.; Hinckley, A.C.; Yakovenko, A.; Zou, X.; Cui, Y.; Bao, Z.J. Stabilization of hexaaminobenzene in a 2D conductive metal-organic framework for high power sodium storage. Am. Chem. Soc. 2018, 140, 10315-10323. [CrossRef]

19. Chen, G.; Gee, L.B.; Xu, W.; Zhu, Y.; Lezama-Pacheco, J.S.; Huang, Z.; Li, Z.; Babicz, J.T.; Choudhury, S.; Chang, T.-H.; et al. Valence-Dependent Electrical Conductivity in a 3D Tetrahydroxyquinone-Based Metal-Organic Framework. J. Am. Chem. Soc. 2020, 142, 21243-21248. [CrossRef] [PubMed]

20. Park, J.; Hinckley, A.C.; Huang, Z.; Chen, G.; Yakovenko, A.A.; Zou, X.; Bao, Z.J. High Thermopower in a Zn-Based 3D Semiconductive Metal-Organic Framework. Am. Chem. Soc. 2020, 142, 20531-20535. [CrossRef] [PubMed]

21. Rocca, J.D.; Liu, D.; Lin, W. Nanoscale metal-organic frameworks for biomedical imaging and drug delivery. Acc. Chem. Res. 2011, 44, 957-968. [CrossRef]

22. Horcajada, P.; Gref, R.; Baati, T.; Allan, P.K.; Maurin, G.; Couvreur, P.; Férey, G.; Morris, R.E.; Serre, C. Metal-organic frameworks in biomedicine. Chem. Rev. 2012, 112, 1232-1268. [CrossRef]

23. Kreno, L.E.; Leong, K.; Farha, O.K.; Allendorf, M.; van Duyne, R.P.; Hupp, J.T. Metal-Organic Framework Materials as Chemical Sensors. Chem. Rev. 2012, 112, 1105-1125. [CrossRef] [PubMed]

24. Hu, Z.; Deibert, B.J.; Li, J. Luminescent metal-organic frameworks for chemical sensing and explosive detection. Chem. Soc. Rev. 2014, 43, 5815-5840. [CrossRef] [PubMed]

25. Lu, K.; Aung, T.; Guo, N.; Weichselbaum, R.; Lin, W. Nanoscale metal-organic frameworks for therapeutic, imaging, and sensing applications. Adv. Mater. 2018, 30, 1707634. [CrossRef]

26. Cui, Y.; Yue, Y.; Qian, G.; Chen, B. Luminescent functional metal-organic frameworks. Chem. Rev. 2012, 112, 1126-1162. [CrossRef]

27. Lee, J.; Farha, O.K.; Roberts, J.; Scheidt, K.A.; Nguyen, S.T.; Hupp, J.T. Metal-organic framework materials as catalysts. Chem. Soc. Rev. 2009, 38, 1450-1459. [CrossRef]

28. Yoon, M.; Srirambalaji, R.; Kim, K. Homochiral metal-organic frameworks for asymmetric heterogeneous catalysis. Chem. Rev. 2012, 112, 1196-1231. [CrossRef]

29. Wang, X.; Han, X.; Zhang, J.; Wu, X.; Liu, Y.; Cui, Y.J. Homochiral 2D porous covalent organic frameworks for heterogeneous asymmetric catalysis. Am. Chem. Soc. 2016, 138, 12332-12335. [CrossRef] [PubMed]

30. Carmona, F.J.; Maldonado, C.R.; Ikemura, S.; Romão, C.C.; Huang, Z.; Xu, H.; Zou, X.; Kitagawa, S.; Furukawa, S.; Barea, E. Coordination Modulation Method To Prepare New Metal-Organic Framework-Based CO-Releasing Materials. ACS Appl. Mater. Interfaces 2018, 10, 31158-31167. [CrossRef] [PubMed]

31. Roy, S.; Huang, Z.; Bhunia, A.; Castner, A.; Gupta, A.K.; Zou, X.; Ott, S.J. Electrocatalytic Hydrogen Evolution from a CobaloximeBased Metal-Organic Framework Thin Film. Am. Chem. Soc. 2019, 141, 15942-15950. [CrossRef] [PubMed]

32. Doonan, C.; Riccò, R.; Liang, K.; Bradshaw, D.; Falcaro, P. Metal-organic frameworks at the biointerface: Synthetic strategies and applications. Acc. Chem. Res. 2017, 50, 1423-1432. [CrossRef] [PubMed]

33. Groom, C.R.; Bruno, I.J.; Lightfoot, M.P.; Ward, S.C. The Cambridge structural database. Acta Crystallogr. Sect. B Struct. Sci. Cryst. Eng. Mater. 2016, 72, 171-179. [CrossRef] [PubMed]

34. Kolb, U.; Gorelik, T.; Kübel, C.; Otten, M.T.; Hubert, D. Towards automated diffraction tomography: Part I-Data acquisition. Ultramicroscopy 2007, 107, 507-513. [CrossRef]

35. Boullay, P.; Palatinus, L.; Barrier, N. Precession electron diffraction tomography for solving complex modulated structures: The case of $\mathrm{Bi}_{5} \mathrm{Nb}_{3} \mathrm{O}_{15}$. Inorg. Chem. 2013, 52, 6127-6135. [CrossRef]

36. Zhang, D.; Oleynikov, P.; Hovmöller, S.; Zou, X.Z. Collecting 3D electron diffraction data by the rotation method. Für Krist. 2010, 225. [CrossRef]

37. Wan, W.; Sun, J.; Su, J.; Hovmöller, S.; Zou, X.J. Three-dimensional rotation electron diffraction: Software RED for automated data collection and data processing. Appl. Crystallogr. 2013, 46, 1863-1873. [CrossRef]

38. Gemmi, M.; Oleynikov, P.Z. Scanning reciprocal space for solving unknown structures: Energy filtered diffraction tomography and rotation diffraction tomography methods. Z. Krist.-Cryst. Mater. 2013, 228, 51-58. [CrossRef]

39. Shi, D.; Nannenga, B.L.; Iadanza, M.G.; Gonen, T. Three-dimensional electron crystallography of protein microcrystals. eLife 2013, 2, e01345. [CrossRef]

40. Nederlof, I.; van Genderen, E.; Li, Y.-W.; Abrahams, J.P. A Medipix quantum area detector allows rotation electron diffraction data collection from submicrometre three-dimensional protein crystals. Acta Crystallogr. D Biol. Crystallogr. 2013, 69, 1223-1230. [CrossRef]

41. Nannenga, B.L.; Shi, D.; Leslie, A.G.W.; Gonen, T. High-resolution structure determination by continuous-rotation data collection in MicroED. Nat. Methods 2014, 11, 927-930. [CrossRef] [PubMed]

42. Gemmi, M.; la Placa, M.G.I.; Galanis, A.S.; Rauch, E.F.; Nicolopoulos, S.J. Fast electron diffraction tomography. Appl. Crystallogr. 2015, 48, 718-727. [CrossRef]

43. Cichocka, M.O.; Ångström, J.; Wang, B.; Zou, X.; Smeets, S.J. High-throughput continuous rotation electron diffraction data acquisition via software automation. Appl. Crystallogr. 2018, 51, 1652-1661. [CrossRef] [PubMed]

44. Plana-Ruiz, S.; Krysiak, Y.; Portillo, J.; Alig, E.; Estradé, S.; Peiró, F.; Kolb, U. Fast-ADT: A fast and automated electron diffraction tomography setup for structure determination and refinement. Ultramicroscopy 2020, 211, 112951. [CrossRef] [PubMed] 
45. Gemmi, M.; Mugnaioli, E.; Gorelik, T.E.; Kolb, U.; Palatinus, L.; Boullay, P.; Hovmöller, S.; Abrahams, J.P. 3D electron diffraction: The nanocrystallography revolution. ACS Cent. Sci. 2019, 5, 1315-1329. [CrossRef]

46. Huang, Z.; Grape, E.S.; Li, J.; Inge, A.K.; Zou, X. 3D electron diffraction as an important technique for structure elucidation of metal-organic frameworks and covalent organic frameworks. Coord. Chem. Rev. 2021, 427, 213583. [CrossRef]

47. Huang, Z.; Willhammar, T.; Zou, X. Three-dimensional electron diffraction for porous crystalline materials: Structural determination and beyond. Chem. Sci. 2021, 12, 1206-1219. [CrossRef]

48. Thomson, G.P.; Reid, A. Diffraction of cathode rays by a thin film. Nature 1927, 119, 890. [CrossRef]

49. Vainshtein, B.K. Structure Analysis by Electron Diffraction; Pergamon Press: Oxford, NY, USA, 1964.

50. Nicolopoulos, S.; Gonzalez-Calbet, J.M.; Vallet-Regi, M.; Corma, A.; Corell, C.; Guil, J.M.; Perez-Pariente, J.J. Direct phasing in electron crystallography: Ab initio determination of a new MCM-22 zeolite structure. Am. Chem. Soc. 1995, 117, 8947-8956. [CrossRef]

51. Dorset, D.L. Electron crystallography-accomplishments and challenges. Acta Crystallogr. A 1998, 54, 750-757. [CrossRef]

52. Weirich, T.E.; Zou, X.; Ramlau, R.; Simon, A.; Cascarano, G.L.; Giacovazzo, C.; Hovmöller, S. Structures of nanometre-size crystals determined from selected-area electron diffraction data. Acta Crystallogr. A 2000, 56, 29-35. [CrossRef] [PubMed]

53. Wagner, P.; Terasaki, O.; Ritsch, S.; Nery, J.G.; Zones, S.I.; Davis, M.E.; Hiraga, K.J. Electron diffraction structure solution of a nanocrystalline zeolite at atomic resolution. Phys. Chem. B 1999, 103, 8245-8250. [CrossRef]

54. Zou, X.; Hovmöller, S. Electron crystallography: Imaging and single-crystal diffraction from powders. Acta Crystallogr. A 2008, 64, 149-160. [CrossRef] [PubMed]

55. Kolb, U.; Mugnaioli, E.; Gorelik, T.E. Automated electron diffraction tomography-A new tool for nano crystal structure analysis. Cryst. Res. Technol. 2011, 46, 542-554. [CrossRef]

56. Palatinus, L.; Brázda, P.; Jelínek, M.; Hrdá, J.; Steciuk, G.; Klementová, M. Specifics of the data processing of precession electron diffraction tomography data and their implementation in the program PETS2.0. Acta Crystallogr. Sect. B Struct. Sci. Cryst. Eng. Mater. 2019, 75, 512-522. [CrossRef]

57. Huang, Z.; Seo, S.; Shin, J.; Wang, B.; Bell, R.G.; Hong, S.B.; Zou, X. 3D-3D topotactic transformation in aluminophosphate molecular sieves and its implication in new zeolite structure generation. Nat. Commun. 2020, 11, 3762. [CrossRef]

58. Yun, Y.; Wan, W.; Rabbani, F.; Su, J.; Xu, H.; Hovmöller, S.; Johnsson, M.; Zou, X.J. Phase identification and structure determination from multiphase crystalline powder samples by rotation electron diffraction. Appl. Crystallogr. 2014, 47, 2048-2054. [CrossRef]

59. Denysenko, D.; Grzywa, M.; Tonigold, M.; Streppel, B.; Krkljus, I.; Hirscher, M.; Mugnaioli, E.; Kolb, U.; Hanss, J.; Volkmer, D. Elucidating Gating Effects for Hydrogen Sorption in MFU-4-Type Triazolate-Based Metal-Organic Frameworks Featuring Different Pore Sizes. Chem. Eur. J. 2011, 17, 1837-1848. [CrossRef]

60. Yao, Q.; Gómez, A.B.; Su, J.; Pascanu, V.; Yun, Y.; Zheng, H.; Chen, H.; Liu, L.; Abdelhamid, H.N.; Martín-Matute, B.; et al. Series of highly stable isoreticular lanthanide metal-organic frameworks with expanding pore size and tunable luminescent properties. Chem. Mater. 2015, 27, 5332-5339. [CrossRef]

61. Zhang, Q.; Su, J.; Feng, D.; Wei, Z.; Zou, X.; Zhou, H.-C. Piezofluorochromic metal-organic framework: A microscissor lift. J. Am. Chem. Soc. 2015, 137, 10064-10067. [CrossRef]

62. Feng, D.; Liu, T.-F.; Su, J.; Bosch, M.; Wei, Z.; Wan, W.; Yuan, D.; Chen, Y.-P.; Wang, X.; Wang, K.; et al. Stable metal-organic frameworks containing single-molecule traps for enzyme encapsulation. Nat. Commun. 2015, 6, 5979. [CrossRef]

63. Jiang, J.; Jorda, J.L.; Yu, J.; Baumes, L.A.; Mugnaioli, E.; Diaz-Cabanas, M.J.; Kolb, U.; Corma, A. Synthesis and structure determination of the hierarchical meso-microporous zeolite ITQ-43. Science 2011, 333, 1131-1134. [CrossRef] [PubMed]

64. Smeets, S.; Wan, W.J. Serial electron crystallography: Merging diffraction data through rank aggregation. Appl. Crystallogr. 2017, 50, 885-892. [CrossRef]

65. Simancas, J.; Simancas, R.; Bereciartua, P.J.; Jorda, J.L.; Rey, F.; Corma, A.; Nicolopoulos, S.; Das, P.P.; Gemmi, M.; Mugnaioli, E.J. Ultrafast electron diffraction tomography for structure determination of the new zeolite ITQ-58. Am. Chem. Soc. 2016, 138, 10116-10119. [CrossRef] [PubMed]

66. Gemmi, M.; Lanza, A.E. 3D electron diffraction techniques. Acta Crystallogr. Sect. B Struct. Sci. Cryst. Eng. Mater. 2019, 75, 495-504. [CrossRef] [PubMed]

67. Kabsch, W. Integration, scaling, space-group assignment and post-refinement. Acta Crystallogr. D Biol. Crystallogr. 2010, 66, 133-144. [CrossRef] [PubMed]

68. Winter, G.; Waterman, D.G.; Parkhurst, J.M.; Brewster, A.S.; Gildea, R.J.; Gerstel, M.; Fuentes-Montero, L.; Vollmar, M.; MichelsClark, T.; Young, I.D.; et al. DIALS: Implementation and evaluation of a new integration package. Acta Crystallogr. Sect. Struct. Biol. 2018, 74, 85-97. [CrossRef]

69. Battye, T.G.G.; Kontogiannis, L.; Johnson, O.; Powell, H.R.; Leslie, A.G.W. iMOSFLM: A new graphical interface for diffractionimage processing with MOSFLM. Acta Crystallogr. D Biol. Crystallogr. 2011, 67, 271-281. [CrossRef] [PubMed]

70. Sheldrick, G.M. A short history of SHELX. Acta Crystallogr. A 2008, 64, 112-122. [CrossRef]

71. Sheldrick, G.M. Crystal structure refinement with SHELXL. Acta Crystallogr. Sect. Found. Adv. 2015, 71, 3-8. [CrossRef] [PubMed]

72. Burla, M.C.; Caliandro, R.; Carrozzini, B.; Cascarano, G.L.; Cuocci, C.; Giacovazzo, C.; Mallamo, M.; Mazzone, A.; Polidori, G.J. Crystal structure determination and refinement via SIR2014. Appl. Crystallogr. 2015, 48, 306-309. [CrossRef]

73. Petříček, V.; Dušek, M.; Palatinus, L.Z. Crystallographic computing system JANA2006: General features. Z. Krist.-Cryst. Mater. 2014, 229. [CrossRef] 
74. Gallagher-Jones, M.; Ophus, C.; Bustillo, K.C.; Boyer, D.R.; Panova, O.; Glynn, C.; Zee, C.-T.; Ciston, J.; Mancia, K.C.; Minor, A.M.; et al. Nanoscale mosaicity revealed in peptide microcrystals by scanning electron nanodiffraction. Commun. Biol. 2019, 2, 1-8.

75. Bücker, R.; Hogan-Lamarre, P.; Mehrabi, P.; Schulz, E.C.; Bultema, L.A.; Gevorkov, Y.; Brehm, W.; Yefanov, O.; Oberthür, D.; Kassier, G.H.; et al. Serial protein crystallography in an electron microscope. Nat. Commun. 2020, 11, 996. [CrossRef] [PubMed]

76. Wang, B.; Zou, X.; Smeets, S. Automated serial rotation electron diffraction combined with cluster analysis: An efficient multi-crystal workflow for structure determination. IUCrJ 2019, 6, 854-867. [CrossRef]

77. Smolders, S.; Willhammar, T.; Krajnc, A.; Sentosun, K.; Wharmby, M.T.; Lomachenko, K.A.; Bals, S.; Mali, G.; Roeffaers, M.B.J.; De Vos, D.E.; et al. A Titanium (IV)-Based Metal-Organic Framework Featuring Defect-Rich Ti-O Sheets as an Oxidative Desulfurization Catalyst. Angew. Chem. 2019, 131, 9258-9263. [CrossRef]

78. He, T.; Huang, Z.; Yuan, S.; Lv, X.-L.; Kong, X.-J.; Zou, X.; Zhou, H.-C.; Li, J.-R. Kinetically Controlled Reticular Assembly of a Chemically Stable Mesoporous Ni (II)-Pyrazolate Metal-Organic Framework. J. Am. Chem. Soc. 2020, 142, 13491-13499. [CrossRef]

79. Dou, J.-H.; Arguilla, M.Q.; Luo, Y.; Li, J.; Zhang, W.; Sun, L.; Mancuso, J.L.; Yang, L.; Chen, T.; Parent, L.R.; et al. Atomically precise single-crystal structures of electrically conducting 2D metal-organic frameworks. Nat. Mater. 2020. [CrossRef]

80. Feyand, M.; Mugnaioli, E.; Vermoortele, F.; Bueken, B.; Dieterich, J.M.; Reimer, T.; Kolb, U.; de Vos, D.; Stock, N. Automated Diffraction Tomography for the Structure Elucidation of Twinned, Sub-micrometer Crystals of a Highly Porous, Catalytically Active Bismuth Metal-Organic Framework. Angew. Chem. Int. Ed. 2012, 51, 10373-10376. [CrossRef]

81. Wang, Y.; Takki, S.; Cheung, O.; Xu, H.; Wan, W.; Öhrström, L.; Inge, A.K. Elucidation of the elusive structure and formula of the active pharmaceutical ingredient bismuth subgallate by continuous rotation electron diffraction. Chem. Commun. 2017, 53, 7018-7021. [CrossRef]

82. Hynek, J.; Brázda, P.; Rohlíček, J.; Londesborough, M.G.S.; Demel, J. Phosphinic acid based linkers: Building blocks in metalorganic framework chemistry. Angew. Chem. Int. Ed. 2018, 57, 5016-5019. [CrossRef]

83. Portolés-Gil, N.; Lanza, A.; Aliaga-Alcalde, N.; Ayllón, J.A.; Gemmi, M.; Mugnaioli, E.; López-Periago, A.M.; Domingo, C. Crystalline Curcumin bioMOF Obtained by Precipitation in Supercritical $\mathrm{CO}_{2}$ and Structural Determination by Electron Diffraction Tomography. ACS Sustain. Chem. Eng. 2018, 6, 12309-12319. [CrossRef]

84. Rhauderwiek, T.; Zhao, H.; Hirschle, P.; Döblinger, M.; Bueken, B.; Reinsch, H.; Vos, D.D.; Wuttke, S.; Kolb, U.; Stock, N. Highly stable and porous porphyrin-based zirconium and hafnium phosphonates-electron crystallography as an important tool for structure elucidation. Chem. Sci. 2018, 9, 5467-5478. [CrossRef] [PubMed]

85. Yuan, S.; Qin, J.-S.; Xu, H.-Q.; Su, J.; Rossi, D.; Chen, Y.; Zhang, L.; Lollar, C.; Wang, Q.; Jiang, H.-L.; et al. [Ti $\left.8 \mathrm{Zr}_{2} \mathrm{O}_{12}(\mathrm{COO})_{16}\right]$ cluster: An ideal inorganic building unit for photoactive metal-organic frameworks. ACS Cent. Sci. 2018, 4, 105-111. [CrossRef] [PubMed]

86. Wang, B.; Rhauderwiek, T.; Inge, A.K.; Xu, H.; Yang, T.; Huang, Z.; Stock, N.; Zou, X. A Porous Cobalt Tetraphosphonate Metal-Organic Framework: Accurate Structure and Guest Molecule Location Determined by Continuous-Rotation Electron Diffraction. Chem. Eur. J. 2018, 24, 17429-17433. [CrossRef] [PubMed]

87. Lenzen, D.; Zhao, J.; Ernst, S.-J.; Wahiduzzaman, M.; Inge, A.K.; Fröhlich, D.; Xu, H.; Bart, H.-J.; Janiak, C.; Henninger, S.; et al. A metal-organic framework for efficient water-based ultra-low-temperature-driven cooling. Nat. Commun. 2019, 10, 3025 [CrossRef] [PubMed]

88. Leubner, S.; Zhao, H.; Van Velthoven, N.; Henrion, M.; Reinsch, H.; De Vos, D.E.; Kolb, U.; Stock, N. Expanding the Variety of Zirconium-based Inorganic Building Units for Metal-Organic Frameworks. Angew. Chem. 2019, 131, 11111-11116. [CrossRef]

89. Grape, E.S.; Xu, H.; Cheung, O.; Calmels, M.; Zhao, J.; Dejoie, C.; Proserpio, D.M.; Zou, X.; Inge, A.K. Breathing metal-organic framework based on flexible inorganic building units. Cryst. Growth Des. 2020, 20, 320-329. [CrossRef]

90. Rabe, T.; Pewe, H.; Reinsch, H.; Willhammar, T.; Grape, E.S.; Stock, N. Influence of the substitution pattern of four naphthalenedicarboxylic acids on the structures and properties of group 13 metal-organic frameworks and coordination polymers. Dalton Trans. 2020, 49, 4861-4868. [CrossRef]

91. Rönfeldt, P.; Reinsch, H.; Grape, E.S.; Inge, A.K.; Terraschke, H.; Stock, N.Z. Water-based Synthesis and Properties of a Scandium 1,4-Naphthalenedicarboxylate. Für Anorg. Allg. Chem. 2020, 646, 1373-1379. [CrossRef]

92. Noa, F.M.A.; Grape, E.S.; Brülls, S.M.; Cheung, O.; Malmberg, P.; Inge, A.K.; McKenzie, C.J.; Mårtensson, J.; Öhrström, L.J. Metal-Organic Frameworks with Hexakis(4-carboxyphenyl)benzene: Extensions to Reticular Chemistry and Introducing Foldable Nets. Am. Chem. Soc. 2020, 142, 9471-9481.

93. Leubner, S.; Bengtsson, V.E.G.; Synnatschke, K.; Gosch, J.; Koch, A.; Reinsch, H.; Xu, H.; Backes, C.; Zou, X.; Stock, N.J. Synthesis and Exfoliation of a New Layered Mesoporous Zr-MOF Comprising Hexa-and Dodecanuclear Clusters as Well as a Small Organic Linker Molecule. Am. Chem. Soc. 2020, 142, 15995-16000. [CrossRef]

94. Cichocka, M.O.; Liang, Z.; Feng, D.; Back, S.; Siahrostami, S.; Wang, X.; Samperisi, L.; Sun, Y.; Xu, H.; Hedin, N.; et al. A Porphyrinic Zirconium Metal-Organic Framework for Oxygen Reduction Reaction: Tailoring the Spacing between Active-Sites through Chain-Based Inorganic Building Units. J. Am. Chem. Soc. 2020, 142, 15386-15395. [CrossRef] [PubMed]

95. Huang, Z.; Ge, M.; Carraro, F.; Doonan, C.; Falcaro, P.; Zou, X. Can 3D electron diffraction provide accurate atomic structures of metal-organic frameworks? Faraday Discuss. 2021, 225, 118-132. [CrossRef] 
96. Carraro, F.; Velásquez-Hernández, M.d.; Astria, E.; Liang, W.; Twight, L.; Parise, C.; Ge, M.; Huang, Z.; Ricco, R.; Zou, X.; et al. Phase dependent encapsulation and release profile of ZIF-based biocomposites. Chem. Sci. 2020, 11, 3397-3404. [CrossRef]

97. Grape, E.S.; Flores, J.G.; Hidalgo, T.; Martínez-Ahumada, E.; Gutiérrez-Alejandre, A.; Hautier, A.; Williams, D.R.; O’Keeffe, M.; Öhrström, L.; Willhammar, T.; et al. A Robust and Biocompatible Bismuth Ellagate MOF Synthesized Under Green Ambient Conditions. J. Am. Chem. Soc. 2020, 142, 16795-16804. [CrossRef] [PubMed]

98. Banihashemi, F.; Bu, G.; Thaker, A.; Williams, D.; Lin, J.Y.S.; Nannenga, B.L. Beam-sensitive metal-organic framework structure determination by microcrystal electron diffraction. Ultramicroscopy 2020, 216, 113048. [CrossRef] [PubMed]

99. Basnayake, S.A.; Su, J.; Zou, X.; Balkus, K.J. Carbonate-based zeolitic imidazolate framework for highly selective $\mathrm{CO}_{2}$ capture. Inorg. Chem. 2015, 54, 1816-1821. [CrossRef] 